\title{
Visualizing the Concept Images of Students on Numbers with Combined SOM-Ward Clustering Analysis
}

\author{
Deniz Kaya ${ }^{1 *}$, Gökçe Ok ${ }^{2}$, Cenk Keşan ${ }^{3}$ \\ ${ }^{1}$ Ministry of National Education, Izmir, TURKEY \\ 2 Public Administration Institute for Turkey and Middle East, Ankara, TURKEY \\ ${ }^{3}$ Dokuz Eylul University, Faculty of Education, Izmir, TURKEY
}

Received 5 July 2017 - Revised 16 September 2017 - Accepted 31 October 2017

\begin{abstract}
The purpose of the study is to perform a less-dimensional visualization process for the purpose of determining the images of the students on the concept of number. The Ward clustering analysis combined with the self-organizing map (SOM) was used for this purpose. The conceptual understanding tool, which consisted of the open-ended question "write the first ten things you remember when the term number is mentioned" to the study group, which consisted of 212 fifth grade students. The analysis results showed that students mostly explained the concept of number by associating with mathematics and other sciences with the terms like "addition, subtraction, division, multiplication, fraction, share, equation, cluster, angle, square, rectangle, plus, minus, shape, operation, step, graphics, value, equal, equals", which are related with "operations-calculations" and "mathematical terms". The students mostly established relations with mathematical side of the number. At the end of the study, the dataset obtained from the conceptual understanding tool was used for training the SOM, and a visualization approach that revealed the images of the students on number concept was recommended.
\end{abstract}

Keywords: concept images, number, self-organizing map (SOM), Ward clustering analysis

\section{INTRODUCTION}

\section{The Number Concept}

According to National Mathematics Teachers Council, the number concept has been the basic element of the mathematics teaching (NCTM, 2000). The best evidence for this is the fact that the number concept has gained important roles in covering the daily needs of everyday life, developing problem-solving strategies, discovering the basic concepts and systems, obtaining reasoning and mental operation skills, making sense of arithmetical expressions, and in ensuring the unity of the learning areas. Especially with the spread of the thought claiming that arithmetical development in early ages is very important in human life, and with the internalization of the life-long learning philosophy by masses, the importance of the better comprehension of the number concept has grown even more in the past years. This concept, which is the source of the inter-science communication and a healthy human development rather than being a mere word-phrase, has guided the thoughts of human beings through centuries as a written symbol, and has supported the development of cognitive abilities. In this context, numbers and operations are given more place in many educational curricula in today's world (Eurydice, 2011; Martin, Mullis, Foy \& Stanco, 2012; MEB, 2013; NAEP, 2006; NCTM, 2006; OECD, 2012), because children acquire the information and skills that will be the basis of their future lives and learn about the real life situations through numbers (Artut \& Tarım, 2006). As a matter of fact, the idea claiming that it is one of the basic skills that are required for the development of mathematical thinking (Olkun, Fidan \& Özer, 2013), and the notion that the mathematical teaching from the preschool years until $12^{\text {th }}$ grade must be based on numbers, support these viewpoints (NCTM, 2000). 


\section{Contribution of this paper to the literature}

- Studies show that students develop concepts and principles before they develop mathematical skills and operations.

- Many concepts like the number concept existing in the mathematics teaching field have critical importance for the mathematical and mental developments of children.

- In all educational levels, mainly in preschool, and in primary and secondary education levels, the number concept has an important place in the development of mathematical skills. In this respect, to determine how the cognitive structures of students on number concept are formed.

The works about numbers start for the first time when children are around 2 years of age and can count in a routine manner when they touch or point at objects around them (one, two, three,...) (Butterworth, 2005; Carey 2004). These words, that are taught or memorized to children in this age group by their families are shaped with the influence of the environment and become the first verbal experiences in mathematical terms. The number words, which are the most basic elements of arithmetic and the indicators of plurality, are in fact abstract words.

Children become aware of an abstract concept by using objects around them for counting. In this context, knowing the meaning of the numbers by children is considered as the first and most important mathematical development, and in this way, it becomes easier for children to make sense of the things around them, and to learn/acquire many skills such as looking for a solution for a problem, matching, ranking, classifying, and making comparisons (NTCM, 2006).

On the other hand, although the number concept is considered as a multi-dimensional and complex structure, it is considered as a step in children's learning calculations (Brannon \& Van de Walle, 2001). The development of this multi-dimensional concept happens in a long term and in a developmental process, and if one of the steps is skipped, it makes it difficult to move to an upper step (Geary, 1994; Gelman \& Meck, 1983; Gelman \& Gallistel, 1978). The fact that children who do not have the ability to count in a conscious manner when they are in the preverbal period have the innate mechanism of subitizing to perceive small quantities is considered as the most important step of the child development (Wynn, 1992). According to Olkun and Toluk (2003), the development of the number concept in children occurs as follows; (a) verbal counting, (b) regular counting, (c) one-to-one matching, (d) the value of the latest number in counting, (e) the protection of counting, and $(f)$ comparison. However, according to a general consideration, the development of number stems from the cardinal and ordinal properties of the numbers (Siegler, 1991; Van de Walle, 2004). The existence of the number concept in every aspect of life -including all the educational levels- is important. The comprehension and interpretation of the number concept, which is a basic concept, has critical importance for the next educational level. For this reason, one of the basic skills that are needed for the development of mathematical thinking is the understanding of the number concept (Olkun, Fidan \& Özer, 2013).

\section{Concept Images and Cognitive Formations}

No doubt, many concepts like the number concept existing in the mathematics teaching field have critical importance for the mathematical and mental developments of children. Mathematical concepts are, on the one hand, the basic elements of mathematics teaching, and on the other hand, they are the key words in the development of mathematical language. Studies show that students develop concepts and principles before they develop mathematical skills and operations (Siegler, 1991). Because of this property, many educational programs are developed on understanding mathematical concepts and systems (Eurydice, 2011; MEB, 2013; NCTM, 2000; OECD, 2004). The most powerful reason of this understanding is the fact that concepts facilitate learning, make benefit for communication, and help to discriminate between imagination and reality (Martorella, 1991). Otherwise, if concept unity is not ensured in learners, this situation may cause concept conflicts. In this context, Tall and Vinner (1981) developed concept definition and concept image models to analyze conceptual thoughts. Concept definition is the model that refers to the discrimination between two concepts; and concept image includes the mental images about the concept. Meanwhile, concept image is also defined as the collection of symbols, signs, and the total cognitive structures interrelated with the mathematical concept, which exists in the mind (Tall \& Vinner, 1981). The most striking definition on concept image is the definition claiming that "it refers to all visual images formed in the mind of a person about a given concept" (Vinner, 1983). Concept images are constantly renewable depending on the individual maturity, new stimuli and experiences; and they always change (Giraldo, Tall \& Carvalho, 2003; Vincent, LaRue, Sealey \& Engelke, 2015). For this reason, concept image develops in years, and does not always have to be consistent (Tossavainen, Attorps \& Väisänen, 2012). On the other hand, concept image consists of a series of processes and structures about the concept. Different parts of the concept image are activated according to the needs of the students at a certain time. This active part of concept image is also called as the stimulated concept image (Tall \& Vinner, 1981). According to Vinner (1983), there are two different "cells" in an individual, which are 
the concept definition and concept image. Although these cells are independent from each other, they may have an interaction between them. As a matter of fact, during the formation of the concept, the relation between the concept image and concept definition must be mutual (Nordlander \& Nordlander, 2012). In this respect, during the learning of many subjects in mathematics, there may be a mental image and some definitions on this image about the concepts in the thoughts of individuals. These conceptual tissues may be drawings, lines, figures, shapes, symbols, depictions, even daily life events that are encoded in the memory of the individual. For example, when the word "circle" is heard, some structures that are relevant or not relevant like circle, diameter, radius, circumference, $\pi$, area, angle, surrounding angle, central angle, curve and some elements from daily life [bagel, pastry, plate, pizza, ring, wheel, clock, the earth, necklace] may appear in the memory. Tall and Vinner (1981) interpreted this situation as the stimulation of the information about the concept in our memory when the name of it is heard. According to this understanding, when a student visualizes a concept, s/he forms a mental model or a symbol that is consistent with it (Nordlander \& Nordlander, 2012).

According to Barnard and Tall (1997), each and every bit of the concept image on which the attention of the individual is focused at one certain moment is called as cognitive unit. Cognitive units may consist of canonical thoughts as well as symbols, theorems, representations, attributes or other aspects of the concept (Giraldo, Tall \& Carvalho, 2003). According to Bingolbali and Monaghan (2008), the development of concept images in students, and how they will establish the connections between image-definition cells are related closely with their learning experiences and their departments. In this respect, it is understood that the formal definition of the relevant concept as well as the discourses of the learners about the definition, mental images of the concept and all of the internalization processes may influence the quality of the concept image (Tall \& Vinner, 1981; Vinner, 1983). The multiple and flexible connections especially among cognitive units are important attributes in acquiring an important idea and even in developing a strong mathematical thought (Barnard \& Tall, 1997). Despite all these explanations, it is extremely difficult to obtain an idea on the stimulated concept images of the students. After Tall and Vinner (1981) developed the concept definition and concept image models, many studies have been conducted on similar models in international field (Altiparmak \& Özdoğan, 2010; Bruno \& Martinon, 1999; Habegger, 2010; Rogers, 2008; Trovato, 2013). When the studies conducted on this topic are examined it is observed that although the majority of them were conducted on the developmental stages of numbers in children and on the cardinal and ordinal properties of number, there are limited studies conducted on how students perceive numbers and on concept images (Olkun, Fidan \& Özer, 2013; Siegler, 1991; Van de Walle, 2004; Wynn, 1992). When all the above mentioned studies are considered, it is possible to conclude that numbers are the free formations of the human mind; and they serve as a tool in comprehending the difference between the things in a sharper and easier manner (Dedekind, 1963). In all educational levels, mainly in preschool, and in primary and secondary education levels, the number concept has an important place in the development of mathematical skills. In this respect, to determine how the cognitive structures of students on number concept are formed, and to find a structure that will reveal the concept images of students were the basic starting points of the present study.

\section{Artificial Neural Networks (ANNs)}

Artificial Neural Networks (ANNs) were designed in 1943 by McCulloch and Pitts as an algorithmic model formed by the weighted sum of the inputs by considering the functionality of the human brain. These networks consist of simple operational elements [neurons] that aim to store the data obtained by experience, and use them later. They also consist of parallel connections [synapses] among each other (Kulkarni, 1994). In this respect, ANN is a systematic structure that consists of a number of neurons connected to each other in a parallel manner establishing interactions with real world samples (Haykin, 1994; Kohonen, 2001). Layers occur with the togetherness of the neurons on the same plain (Haykin, 1994). ANN consists of three layers, which are the input layer, the intermediary layer and the output layer (Elmas, 2016). The operation steps of ANNs are run in three stages. Each of the inputs shown with " $x_{i}$ " symbol is multiplied with " $w$ " weight. Simply, these products are added with the threshold value $\theta_{j}$ and the operation is made with the efficiency function in order to obtain the result, and then the $y_{i}$ output is received (Elmas, 2016). According to the biological neural network structure, synapses represent the weights, dendrites represent the addition function, the cell body represents the transfer function, and the axons represent the cell output. ANNs occur with accurate connections among learning neurons and by assigning proper values to these connections. The initial values are generally assigned in a random manner. Depending on the defined learning algorithm and on the error values, the values are renewed and the weights are adjusted to give the desired function (Elmas, 2016; Haykin, 1994; Nabiyev, 2016).

\section{Self-Organizing Map (SOM)}

Self-Organizing Map (SOM) was developed in 1982 by Kohonen for the purpose of clustering and visualizing the data in situations where categories are not definite (Flexer, 2001; Kohonen, 2001). SOM is an uncounseled neural network model that converts similar bundles of high-dimensional inputs on the map into low-dimensional 
topology (Kohonen, 2001). SOM is activated by acting together with a competitive learning algorithm and by gaining only one neuron. The output neuron that wins the competition is called as the winning neuron or the best matching unit (BMU) (Haykin, 1994; Kohonen, 2001). SOM consists of artificial neurons that have the weight vector in order to form a topographic map (Herbert \& Yao, 2009). The basic logic of SOM is the fact that the neurons connect to each other in the form of $m x n$ to form a 2D map. These connections are connected to each other according to the topological connections (Cabanes, Bennani, \& Fresneau, 2012). In general terms, the following steps are followed for the SOM learning algorithm:

Step 1: Determining the initial weight values between $[0,1]$ in a random order, and the adjustment of learning coefficients.

Step 2: Calculating the distance between each entry design and weight matrix according to Euclid distance measurement.

Step 3: Determining the winning neuron.

$$
c=\arg \left(\min _{1 \leq i \leq m n}\left\{\left\|w_{i}(t)-x(t)\right\|\right\}\right)
$$

In this equation $\|$.$\| represents the Euclid distance measurement. x(t)$ and $w_{i}(t)$, respectively, are the entry and weight vector of $i$ neuron in $t$ iteration.

Step 4: Renewal of weight vector of the neurons.

$$
w_{i}(t+1)=w_{i}(t)+h_{c i}(t)\left[x(t)-w_{i}(t)\right]
$$

In this equation, $t$ is the learning step; $c$ is the index of the BMU. The $h_{c i}(t)$ Gauss neighboring function is given in equation (3).

$$
h_{c i}(t)=a(t) \exp \left(-\frac{\left\|r_{c}-r_{i}\right\|^{2}}{2 \sigma^{2}(t)}\right)
$$

Step 5: Repeating these steps for all input data (Kohonen, 2001; Kohenen et al., 2000).

In this study, the SOM method was preferred because it is capable of organizing many datasets in a regular manner as well as forming data maps.

\section{Combined SOM-Ward Clustering Analysis}

Ward clustering analysis is a clustering method in grouping hierarchical manner. The basic understanding of the Ward method is to minimize the information loss that may occur with the joining of two clusters, and make the smallest variance optimum in the cluster (Aldenderfer \& Blashfield, 1984; Ward, 1963). As the measurement of the homogeneity, the Error Sum of Squares (ESS) in the clusters is used (Chatfield \& Collins, 1980; Sharma, 1996). Initially, each observation is accepted as a cluster. If there are $\mathrm{N}$ observations, $\mathrm{ESS}_{\mathrm{k}}=0, \mathrm{k}=1,2,3, \ldots, \mathrm{N}$ and $\mathrm{ESS}=0$. The formula on ESS is given in equation (4).

$$
E S S=\sum_{i=1}^{K} \sum_{j=1}^{n_{i}}\left(x_{i j}-\bar{x}_{i}\right)^{\prime}\left(x_{i j}-\bar{x}_{i}\right)
$$

The formula given in equation (4) is applied in the same manner for each cluster. $x_{i}$ is the multi-variable measurement related to $j$ observations; and $\bar{x}$ is the measurement of all observations. The node character of the map and the topological positions of the clusters are used as the measurement tool in the SOM-Ward clustering method, which is a modified special form of Ward method. The formula given in equation (5) is made use of for the $d_{r s}^{\prime}$ distance between $r$ and $s$; and $n_{r}$ and $n_{s}$ are the numbers of the recorded data; $\bar{x}_{r}$ and $\bar{x}_{s}$ are the node vectors.

$$
d_{r s}^{\prime}=\left\{\begin{array}{c}
d_{r s} \text { if clusters } r \text { and } s \text { are adjacent }, \\
\infty \text { differently }
\end{array}\right.
$$

\section{METHODOLOGY}

In terms of the SOM-Ward clustering technique, open-ended questions were directed to the students and an empirical method was applied. In this respect, the study is a phenomenography study intended to analyze how students perceive the number concept. According to Marton (1994), phenomenography is a method that helps people "map" the objects, the phenomena and the experiences on the world where they live, and uses different qualitative ways like conceptualizing, perception and understanding. The most powerful side of this approach is that it may analyze how people comprehend certain situations and topics, how they make sense of these, and how they interpret them (Marton \& Booth, 1997). With regarding to reveal what students perceive or understand the same concept, this method has become an accepted and preferred method in educational research (Entvistle, 1997). 


\section{Research Group}

The study group consisted of 212 students who were studying at $5^{\text {th }}$ grades in a state secondary school in the city center of Izmir in 2015-2016 academic year. 108 of the students were female (50.9\%) and 104 were male (49.1\%). The socio-economic status of the students who were selected randomly was generally in middle level.

\section{Data Collection Tool}

The conceptual understanding tool, which consisted of the open-ended question "write the first ten things you remember when the term number is mentioned", was used as the data collection tool. In order to ensure the content and fitness validity of the measurement tool, which was developed by the authors, the viewpoints of 5 instructors who were specialists in their fields were received. In addition to this, in order to clarify some unclear concepts, which were possibly not to be understood by students, the teacher and student viewpoints were received. Phenomenography research is based on fundamental differences in the way to obtain experience with any phenomenon (Trigwell, 2006). On the one hand, in the process of phenomenography research, it is mentioned how various phenomena are understood in different ways and then, in respect of resultant categories, different insights are systematically separated (Ashworth \& Lucas, 1998). In the context of phenomenography approach where appears in the field of qualitative research, students' answers that were stated considering their perceptions on the concept of number was associated with appropriate categories. In this way, students' perceptions on the concept of number was categorized so resultant categories were interrelated. The main feature of these categories was arranged according to contents of students' answers. Similar expressions was treated in the same category and these expressions were named to reflect the common features. For example, when students' responses relating the concept of number were analyzed, it was seem that "license plates" answer had been placed in the "daily life" category. Also "love" answer had been placed in the "abstract expression" category. While categories were created, it had been paying particular attention to provide a combination of cognitive associations. Because it was given an importance to created categories being logical, clear and hierarchical with each other (Marton \& Booth, 1997). Then, each different category involving qualitative terms was converted into quantitative data by giving a code. Matlab and Viscovery SOMine had been used in the analysis of quantitative data.

\section{FINDINGS}

\section{Conceptual Understanding Measurement Tool Results}

In this study, the concept images of the students at $5^{\text {th }}$ grade were determined. When the first 10 answers given by the students on the number concept were examined, it was observed that the most-frequently repeated expressions were "addition, subtraction, division, multiplication, fraction, share, equation, term, cluster, angle, square, rectangle, plus, minus, shape, operation, step, graphics, value, equal, equals" and similar terms in daily life; and it was also observed that they explained these terms by associating them with "operations/computations" and "mathematical terms". Aside from these, there were also some expressions like natural numbers, successive numbers, number patterns, exponential numbers, and the step values of the numbers, cardinal numbers, the biggest and smallest numbers, and decrease-increase of numbers. Infinity, infinite numbers, easy, mind, dream, difficulty, curiosity, fear, and love were also included in the answers given by the students. The structure of the SOM weight positions of the variables analyzed with Matlab is given in Figure 1. The areas where the connections are intense show the similarity of the students' answers. 


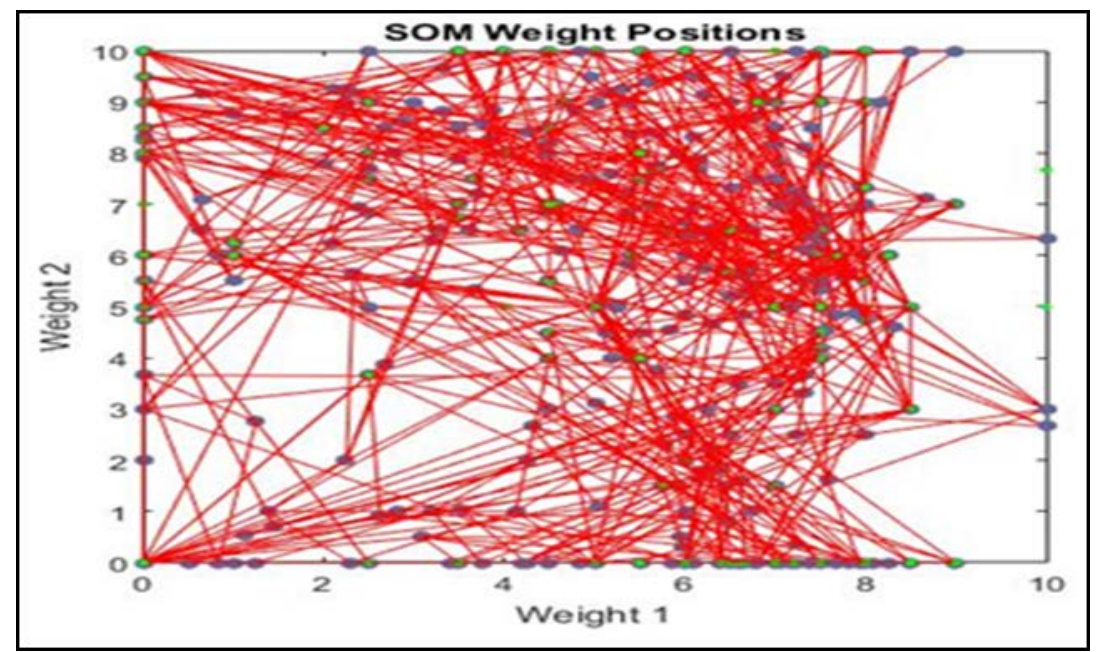

Figure 1. SOM weight positions

Table 1. The themes determined according to the viewpoints of the students

\begin{tabular}{|c|c|c|c|}
\hline Category No & Category Name & Explanation & Sample Answers \\
\hline 1 & $\begin{array}{l}\text { Operations and } \\
\text { calculations }\end{array}$ & $\begin{array}{l}\text { There are expressions about the } \\
\text { operation and calculation of the } \\
\text { numbers in this category. }\end{array}$ & $\begin{array}{l}\text { Addition, subtraction, division, multiplication, problems, } \\
\text { the averages of the numbers. }\end{array}$ \\
\hline 2 & $\begin{array}{l}\text { Mathematical } \\
\text { terms }\end{array}$ & $\begin{array}{l}\text { There are mathematical } \\
\text { expressions associated with the } \\
\text { number concept in this category. }\end{array}$ & $\begin{array}{l}\text { Number, fraction, share, equation, term, cluster, angle, } \\
\text { square, rectangle, plus, minus, shape, operation, table, } \\
\text { step, graphics, value, equal, equals }\end{array}$ \\
\hline 3 & $\begin{array}{l}\text { Number } \\
\text { property }\end{array}$ & $\begin{array}{l}\text { There are expressions on the } \\
\text { properties of the number concept } \\
\text { in this category. }\end{array}$ & $\begin{array}{l}\text { Natural numbers, successive numbers, number patterns, } \\
\text { exponential numbers, the stepvalue of the numbers, } \\
\text { cardinal numbers, the biggest and smallest numbers, the } \\
\text { decrease/increase of the numbers. }\end{array}$ \\
\hline 4 & Daily life & $\begin{array}{l}\text { There are expressions on everyday } \\
\text { life events associated with the } \\
\text { number concept in this category. }\end{array}$ & $\begin{array}{l}\text { Hour, scientist, school, flower, insect, exam, teacher, } \\
\text { world, car license plates, telephone numbers, finger, } \\
\text { abacus, money, puzzle, age, ruler, class attendance sheet, } \\
\text { chicken. }\end{array}$ \\
\hline 5 & $\begin{array}{c}\text { Abstract } \\
\text { expressions }\end{array}$ & $\begin{array}{l}\text { There are expressions that are not } \\
\text { perceived with the five sensory } \\
\text { organs and that are known by } \\
\text { emotions in this category. }\end{array}$ & $\begin{array}{l}\text { Infinity, infinite numbers, easy, mind, dream, difficulty, } \\
\text { curiosity, fear, love. }\end{array}$ \\
\hline
\end{tabular}

Table 2. The codes of the expressions given by students

\begin{tabular}{ccccccccccc}
\hline Student & $\mathbf{R}_{\mathbf{1}}$ & $\mathbf{R}_{\mathbf{2}}$ & $\mathbf{R}_{\mathbf{3}}$ & $\mathbf{R}_{\mathbf{4}}$ & $\mathbf{R}_{\mathbf{5}}$ & $\mathbf{R}_{\mathbf{6}}$ & $\mathbf{R}_{\mathbf{7}}$ & $\mathbf{R}_{\mathbf{8}}$ & $\mathbf{R}_{\mathbf{9}}$ & $\mathbf{R}_{\mathbf{1 0}}$ \\
\hline $\mathrm{S}_{103}$ & 2 & 2 & 4 & 4 & 4 & 4 & 4 & 1 & 1 & 2 \\
\hline $\mathrm{S}_{104}$ & 2 & 4 & 4 & 2 & 1 & 1 & 1 & 2 & 2 & 1 \\
\hline $\mathrm{S}_{105}$ & 2 & 1 & 1 & 2 & 1 & 1 & 2 & 1 & 2 & 4 \\
\hline $\mathrm{S}_{106}$ & 2 & 1 & 1 & 1 & 4 & 4 & 2 & 2 & 2 & 1 \\
\hline $\mathrm{S}_{107}$ & 2 & 1 & 1 & 1 & 1 & 2 & 4 & 2 & 2 & 2 \\
\hline $\mathrm{S}_{108}$ & 2 & 2 & 2 & 2 & 1 & 1 & 1 & 1 & 3 & 3 \\
\hline $\mathrm{S}_{109}$ & 2 & 2 & 2 & 1 & 1 & 1 & 1 & 2 & 4 & 4 \\
\hline
\end{tabular}

\section{SOM-Ward Clustering Analysis}

The results obtained from the open-ended conceptual measurement tool that was used on students were used in SOM-Ward clustering model. The answers given by students on the number concept are given in 5 categories (Table 1). In determining the categories, the intensity of the answers given by the students to open-ended questions were influential. In this respect, similar expressions were merged in certain categories.

Then, a code was defined for each category (Table 2). In this context, the answers of each student were encoded in order $\left(S_{1}, S_{2}, \ldots, S_{212}\right)$ and the data obtained were ranked $\left(R_{1}, R_{2}, \ldots, R_{10}\right)$. 
Table 3. Rank averages of the expressions of the students

\begin{tabular}{cccccc}
\hline Student & $\mathbf{X}_{\mathbf{1}}$ & $\mathbf{X}_{\mathbf{2}}$ & $\mathbf{X}_{\mathbf{3}}$ & $\mathbf{X}_{\mathbf{4}}$ & $\mathbf{X}_{\mathbf{5}}$ \\
\hline $\mathrm{S}_{103}$ & 8.5 & 4.33 & 0 & 5 & 0 \\
\hline $\mathrm{S}_{104}$ & 7 & 5.5 & 0 & 2.5 & 0 \\
\hline $\mathrm{S}_{105}$ & 4.8 & 5.25 & 0 & 5.5 & 0 \\
\hline $\mathrm{S}_{106}$ & 4.75 & 6.25 & 0 & 7 & 0 \\
\hline $\mathrm{S}_{107}$ & 3.5 & 6.8 & 0 & 0 & 0 \\
\hline $\mathrm{S}_{108}$ & 6.5 & 2.5 & 9.5 & 9.5 & 0 \\
\hline $\mathrm{S}_{109}$ & 5.5 & 3.5 & 0 & &
\end{tabular}

Table 4. SOM-Ward clustering entry data

\begin{tabular}{cccccc}
\hline Student & $\mathbf{X}_{\mathbf{1}}$ & $\mathbf{X}_{\mathbf{2}}$ & $\mathbf{X}_{\mathbf{3}}$ & $\mathbf{X}_{\mathbf{4}}$ & $\mathbf{X}_{\mathbf{5}}$ \\
\hline $\mathrm{S}_{103}$ & 2.5 & 6.66 & 0 & 6 & 0 \\
\hline $\mathrm{S}_{104}$ & 4 & 5.5 & 0 & 1 & 0 \\
\hline $\mathrm{S}_{105}$ & 6.2 & 5.75 & 0 & 5.5 & 0 \\
\hline $\mathrm{S}_{106}$ & 6.25 & 4.75 & 0 & 4 & 0 \\
\hline $\mathrm{S}_{107}$ & 7.5 & 4.2 & 0 & 0 & 0 \\
\hline $\mathrm{S}_{108}$ & 4.5 & 8.5 & 1.5 & 1.5 & 0 \\
\hline $\mathrm{S}_{109}$ & 5.5 & 7.5 & 0 &
\end{tabular}

Although there were no differences between the data separated into categories in Table 2, the standardization process was applied because of the values in the dataset, because the smallest " 1 " and the biggest " 5 " values given for the categories caused that the result of the operation was incorrect. For this reason, a new table was formed in order to calculate and see what students wrote on number concept in what range. For this purpose, the expressions that had low average ranks on number concept were made to become more important when compared with the expressions with high rank averages. The average rank calculation was made as follows: The answers given by the students on the number concept was categorized from 1 to 5 , and the average rank values $\left(R_{1}, R_{2}, \ldots, R_{5}\right)$ were calculated. Then, these values were added for each line and divided by the total frequency.

For example, theme 4 of the $S_{103}$ student in Table 2 were repeated for five times on $3,4,5,6$ and 7 th ranks. In this context, the average rank was calculated as $(3+4+5+6+7) / 5=5$. In the next step, the data given in Table 3 were converted into a proper dataset in order to educate the SOM, because if an answer in the "operations and calculations" category is written as the first statement, it had the value " 1 " on the list. However, this situation also caused a miscalculation. For example, the students with code $S_{107}$ stated theme 4 only in the $7^{\text {th }}$ rank. For this reason, there is the number 7 under this theme. Both for the purpose of making the dataset become proper for the SOMWard clustering analysis and for not receiving incorrect results from the dataset used in training the SOM, the arrangement was made again so as the number " 1 " would give the lowest relation, and " 10 " would give the highest relation. For this purpose, the data in the evaluation set were subtracted from 11 (Table 4$)$. These data $\left(x_{1}, x_{2}, \ldots, x_{5}\right)$ were used in training the SOM-Ward model. In addition, if the answers of the students on "operations and calculations" were not among the 10 statements, the 0.00 value was given [see Table 4 , first line $\left(h_{3}\right.$ or $\left.h_{5}\right)$ ]. By sodoing, the statements that were never mentioned were approximated to the first and last statements that were given in the dataset.

\section{SOM-Ward Clustering Analysis Results}

In order to determine the concept images of the students on the number concept, the dataset algorithms were used to train the SOM-Ward clustering analysis. In organizing the data obtained from the students, the Matlab and SOMine programs were made use of. In order to evaluate the images of the students on number concept in a more qualified manner, the hierarchical clustering algorithm in the SOMine program in addition to the SOM was used. The purpose here was to ensure that each and every variable was evaluated as a cluster. By doing so, new distance measurement was used for the distances between the clusters. For this purpose, 10 variables obtained from each of the students were used in forming the clusters.

On the other hand, in the clustering stage of SOM-Ward training, the 0.5 tension parameter was used as the measurement of how neurons compete with each other. The clusters that were formed with the Kohonen layer that was obtained as a result of the competition of 1000 neurons used in SOM-Ward clustering analysis are given in Figure 2. The U-matrix was formed by working the Ward basic agglomerative hierarchical clustering technique and the SOM together (Figure 3). In the agglomerative hierarchical clustering technique, each observation is initially given a value as an independent cluster, and then, each cluster is made to form another cluster together with the observation or with the observation cluster that is nearest to it in a repetitive manner until a single cluster that includes all observations is obtained (Yesilbudak, Kahraman \& Karacan, 2011). The dark areas in the U-matrix 


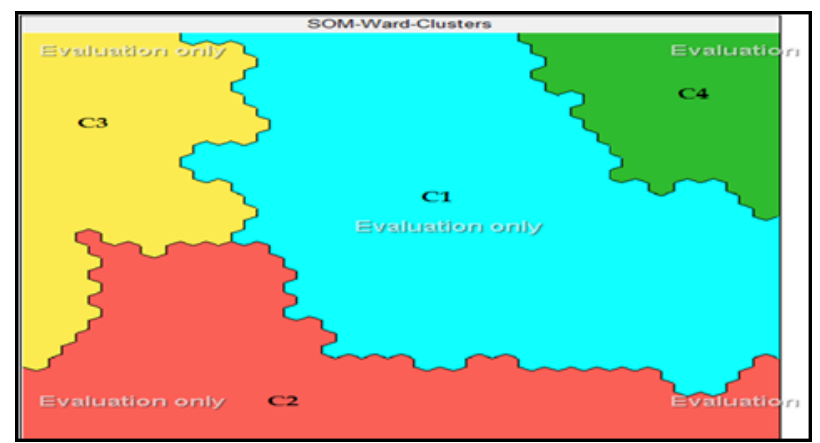

Figure 2. SOM-Ward clustering analysis

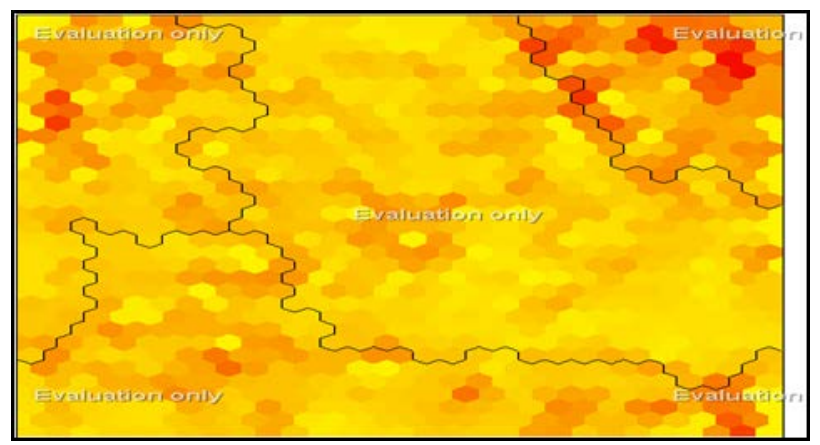

Figure 3. U-matrix

Table 5. Statistical results and clusters

\begin{tabular}{ccccccc}
\hline Cluster & Frequency & Attribute 1 & Attribute 2 & Attribute 3 & Attribute 4 & Attribute 5 \\
\hline C1 & $41.98 \%$ & 6.64 & 6.95 & 1.47 & 2.38 & 0.02 \\
\hline C2 & $28.77 \%$ & 2.03 & 6.95 & 3.83 & 5.38 & 0.05 \\
\hline C3 & $20.28 \%$ & 4.01 & 3.55 & 7.18 & 1.68 & 0.00 \\
\hline C4 & $8.96 \%$ & 6.08 & 6.93 & 2.69 & 3.25 & 5.57 \\
\hline
\end{tabular}

show the areas where the relation between the neurons is weak and light colors show the areas where this relation is strong.

When Figure 3 is examined it is observed that four clusters were formed in the Kohonen layer depending on the trained dataset (Table 4). The data on the observation percentage in the formed clusters and the data on the percentage of the variables in the relevant cluster are given in Table 5. The dark areas in Figure 3 show that the relations between the neurons are low and the light areas show that the relation is strong. With the help of the colors, it is ensured that the cluster cages are separated from each other by determining a limit. The size of the clusters formed in Figure 3 and the effects of the categories on these clusters are given in Table 5. A parameter varying between 0 and 10 is used in order to determine how much a group affects a cluster. As the parameter value approaches to 10, the effect of the group to the cluster is increased. These parameters give the median value of the clusters, and may be expressed as in the following formula in mathematical terms: If $i=(1,2,3,4)$ is the number of the clusters, $j=(1,2,3,4,5)$ is the categories and $e \in \mathrm{R}^{5}$

$C_{i}=\sum_{j=1}^{5}\left(x_{i j} e_{j}\right)$. When this equation is expressed with matrix, the following result is obtained:

$$
\left[\begin{array}{l}
C_{1} \\
C_{2} \\
C_{3} \\
C_{4}
\end{array}\right]=\left[\begin{array}{lllll}
x_{11} & x_{12} & x_{13} & x_{14} & x_{15} \\
x_{21} & x_{22} & x_{23} & x_{24} & x_{25} \\
x_{31} & x_{32} & x_{33} & x_{34} & x_{35} \\
x_{41} & x_{42} & x_{43} & x_{44} & x_{45}
\end{array}\right]\left[\begin{array}{l}
e_{1} \\
e_{2} \\
e_{3} \\
e_{4} \\
e_{5}
\end{array}\right]
$$

According to this result, for example, the coefficient of the themes of the $\mathrm{C}_{1}$ cluster may be expressed as follows:

$$
C_{1}=x_{11} e_{1}+x_{12} e_{2}+x_{13} e_{3}+x_{14} e_{4}+x_{15} e_{5}
$$

When Table 5 is examined it is observed that $41.98 \%$ of the students used C1, 28.77\% used C2, 20.28\% used C3 and $8.96 \%$ used C4 concept images on the "number concept" in the first rank. On the other hand, "operations and calculations" and "mathematical terms" are observed with the highest frequency in C1 cluster; "mathematical terms" and "daily life" in C2 cluster; "number property" in C3 Cluster; and "operations and calculations", "mathematical terms" and "abstract expressions" in C4 clusters. 


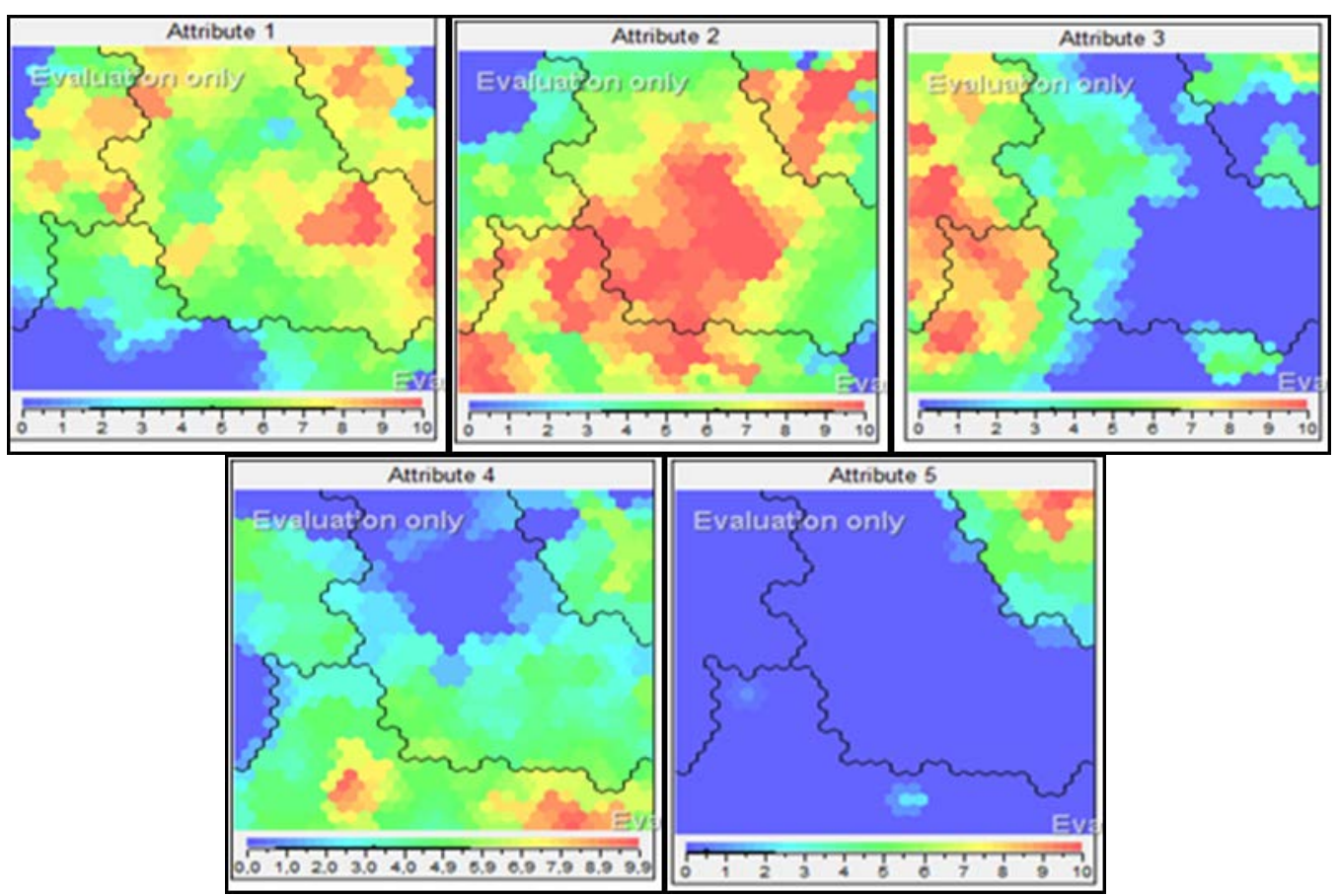

Figure 4. Feature planes for all classes

In Figure 4, the map component plains of the four clusters that were formed with SOM-Ward model are given. The map component plains express the contribution of each variable while the color scale visualizes the distribution of each variable in different clusters. According to the color scale given in the model, the dark-blue areas show that there are no relations (the number " 0 "); while dark-red color indicates that the relation is strong (the number " 10 "). For example, the first map in Figure 4 shows the contribution of the first group, in other words, the "operations and calculations" group to the clusters. According to this map, the first group influenced mostly the C1 and C4 clusters and constituted most part of the cognitive structure, it has the red color in certain areas in C 3 cluster, and is among the first answers given by the students in these areas. When the second map is examined it is observed that the second group exists efficiently in C1, C2 and C4 clusters, and intensifies especially in the middle part of the clusters. In addition, it is also observed that it also exists in a certain amount in the lower part of the cage in C3 cluster. In the third map, it is observed that the third group intensifies in an adjacent manner to cages in C2 and C3 clusters. It is observed in the fourth map that the fourth group intensifies in the lower-right side and in the middle part of the C2 clusters in a little amount. As the last item, in the fifth map, it is observed that the fifth group intensifies in the upper part of the cage in C4 cluster.

\section{CONCLUSION, DISCUSSION AND RECOMMENDATIONS}

The basic justification of the present study was conducting a detailed and less-dimensional visualization operation for the purpose of determining the images of the students on the number concept. For this purpose, clustering analysis was applied with the help of the SOM to the dataset which was obtained from the students on the number concept. The images on the number concept were obtained by transferring the 10 variables from each of the 212 fifth grade students into a 2-Dimensional map. The cognitive structures of the students on the number concept were collected in four clusters, which were C1, C2, C3 and C4. The C1 cluster consists of "operations and calculations", C2 cluster consists of "mathematical terms", C3 cluster consists of "number property", C4 cluster consists of "daily life" and C5 cluster consists of "abstract expressions", the cognitive structures belonging to the concept. On the other hand, different colors in the map component plain provide important clues in understanding the images of the students on the number concept. When the first map in Figure 4 is examined it is observed that the first theme consists of a combination of the red and yellow colors especially in C1, C3 and C4 clusters. We can conclude that the reason for this color relation is the fact that the answers of the students are in the first rank in these areas. Similarly, when the second map is examined it is observed that the second theme has an influence on all clusters. However, as it may be understood from the intensity of the red color in C1, C2 and C4 clusters, the contribution of the theme to these clusters is extremely high. It is observed that the red color intensifies on C2 and $\mathrm{C} 3$ clusters in the third theme, in C2 cluster in the fourth theme, and in the C4 cluster in the fifth theme. In addition to this, when we examine the topographical structure of the clusters, we can claim that especially the relation 
between the second theme and the other clusters is stronger. When the component plain of the second map is examined in detail, it is observed that the red color intensifies at the middle point of the C1, C2 and C4 clusters, and in areas that are close to the cages. This situation shows that the concept images of the students on the number concept have a high-level relation with the "mathematical terms". These findings overlap with the fact that the number concept is one of the basic skills of the students in their daily lives, and with the notion claiming that mathematics should be based on numbers (Artut \& Tarım, 2006; NCTM, 2000).

The other findings, symbols and signs obtained from the component plain of the second map constitute a concrete basis for the concept image definition, which is defined as the collection of the cognitive structures that are related with mathematical concept in the minds of the people, just like the examples in daily life (Tall \& Vinner, 1981). In this context, the cognitive structures on the number concept occur mostly between the "operations and calculations" and "mathematical terms" in C1 clusters; between "mathematical terms" and "daily life" in C2 cluster; between "operations and calculations" and "number property" in C3 cluster, and between "operations and calculations", "mathematical terms" and "abstract expressions" in C4 cluster. Another interesting result of the present study was obtained from the fifth map component plain. In this respect, "abstract expressions", which is the fifth theme, exists only in the C4 cluster and in the upper-right region of the cage. This theme is in a very lowlevel relation with the other themes, and it has formed a cognitive structure with the other clusters. It would be correct to claim that the concept images of the students on the number concept were formed of a single structure.

One of the strong sides of the study is the fact that it enables a clear look at the characteristic properties of the clusters formed with the mental structuring of the number concept of the students by visualization and by using the SOM. For example, the "daily life" in C2 cluster exists clearly in the lower-right corner of the cage in the fourth map component plain. The same theme has a low-level relation in the other clusters. It is expected that such an illustration of the mental structuring between the number concept and daily life situations will bring a different insight on the topic and provide evidence for researchers. On the other hand, when the third map is examined it is observed that the "number property" theme has a close relation with the C2 and C 3 clusters. In this context, it is observed that the concept images of the students on the properties of the number concept are associated with the "operations and calculations" theme. It is expected that by establishing a cause-result relation, this result will reinforce the hypothetical approach claiming that concept images mentioned in the literature may consist of cognitive units, canonical thoughts and may be related with the symbols, theorems, representations, and with several sides of an attribute or a concept (Giraldo, Tall \& Carvalho, 2003; Barnard \& Tall, 1997). The areas where the red color is intense on the map component plain of five different groups also show the efficiency level of the winning neuron. The optimization of the SOMs structure in these areas may be converted into different color combinations providing that the numbers of the output neurons are changed. In addition to this conversion, the topographical structure of the maps may be improved with new organizations that will be made in the learning parameter. Especially the use of variables that are irrelevant with the numbers may make this situation become more understandable. In addition to this, the structure of the SOM may be re-organized by making some new additions and regulations to the dataset obtained from the 212 students, and the data error may also be reorganized. Aside from this, the weights may be adjusted by renewing the weights to perform a desired function depending on the error values and on a defined learning algorithm. By so-doing, these kinds of practices may be tested with different variables to make the clustering analyses have higher performance. However, the most important point is the reliability of the input dataset. As a conclusion, the images of other students on another concept may be visualized with the help of the studies conducted on artificial neural networks, and more detailed mental structures may be defined. It is expected that this study will bring a different viewpoint on a more efficient use of SOMs in the field of education because of the fact that it contains data in high intensity and is successfully used in the visualization of mental perceptions.

\section{REFERENCES}

Aldenderfer, M. S., \& Blashfield, R. K. (1984). Cluster analysis. Beverly Hills: Sage Publications.

Altiparmak, K., \& Özdoğan, E. (2010) A study on the teaching of the concept of negative numbers. International Journal of Mathematical Education in Science and Technology, 41(1), 31-47.

Artut, P. D., \& Tarım, K. (2006). Elementary students' comprehension of place value concept. Journal of Theory and Practice in Education, 2(1), 26-36.

Asworth, P., \& Lucas, U. (1998). What is 'world' of phenomenography? Scandinavian Journal of Educational Research, 42(4), 415-431.

Barnard, A. D., \& Tall, D. O. (1997). Cognitive units, connections, and mathematical proof. In E. Pehkonen, (Ed.), Proceedings of the 21' Annual Conference for the Psychology of Mathematics Education, Vol. 2 (pp. 41-48). Lahti, Finland.

Bingolbali, E., \& Monaghan, J. (2008). Concept image revisited. Educ Stud Math, 68(1), 19-35. 
Brannon, E. M., \& Van de Walle, G. A. (2001). The development of ordinal numerical competence in young children. Cognitive Psychology, 43(1), 53-81.

Bruno, A., \& Martinon, A. (1999). The teaching of numerical extensions: The case of negative numbers. Int. J. Math. Educ. Sci. Technol, 30(6), 789-809.

Butterworth, B. (2005). The development of arithmetical abilities. Journal of Child Psychol Psychiatry, 46(1), 3-18.

Cabanes, G., Bennani, Y., \& Fresneau, D. (2012). Enriched topological learning for cluster detection and visualization. Neural Networks, 32(1), 186-195.

Carey, S. E. (2004). Bootstrapping \& the origin of concepts. Daedalus, 133(1), 59-68.

Chatfield. C., \& Collins. A. J. (1980). Introduction to multivariate analysis. London: Chapman and Hall.

Dedekind, R. (1963). Essays on the theory of numbers. New York: Dover Publications.

Elmas, Ç. (2016). Yapay zekâ uygulamaları [Artificial intelligence applications]. Ankara: Seçkin Yayıncılık.

Entwistle, N. (1997). Introduction: Phenomenography in higher education. Higher Education Research and Development, 16(2), 127-158.

Eurydice (2011). Mathematics education in Europe: Common challenges and national policies. Retrieved from http://eacea.ec.europa.eu/

Flexer, A. (2001). On the use of self-organizing maps for clustering and visualization. Intelligent Data Analysis, 5(5), 373-384.

Geary, D. C. (1994). Children's mathematical development: Research and practical applications. Washington, DC: American Psychological Association.

Gelman, R., \& Gallistel, C. R. (1978). The child's understanding of number. Cambridge, MA: Harvard University Press.

Gelman, R., \& Meck, E. (1983). Preschooler's counting: Principles before skill. Cognition, 13(3), 343-359.

Giraldo, V., Tall, D., \& Carvalho, L. M. (2003). Using theoretical-computational conflicts to enrich the concept image of derivative. Research in Mathematics Education, 5(1), 63-78.

Habegger, L. (2010). Number concept and rhythmic response in early childhood. Music Education Research, 12(3), 269-280.

Haykin, S. (1994). Neural networks: A Comprehensive foundation. New York: MacMillan Publishing Company.

Herbert, J. P., \& Yao, J. T. (2009). A granular computing framework for self-organizing maps. Neurocomputing, 72(1315), 2865-2872.

Kohonen, T. (2001). Self-organizing maps. Berlin: Springer-Verlag.

Kohonen, T., Kaski, S., Lagus, K., Salojarvi, J., Honkela, J., Paatero, V., \& Saarela, A. (2000). Self organization of a massive document collection. IEEE Transactions on Neural Networks, 11(3), 574-585.

Kulkarni, A. D. (1994). Artificial neural network for image understanding. New York: Van Nostrand Reinhold.

Martin, M.O., Mullis, I. V. S., Foy, P., \& Stanco, G. M. (2012). TIMSS 2011 international results in science. Chestnut Hill, MA: TIMSS \& PIRLS International Study Center, Boston College.

Marton, F. (1994). Phenomenography. In T. Husen, and N. Postlethwaite (Eds.), International Encyclopedia of Education (pp. 4424-4429). Oxford: Pergamon.

Marton, F., \& Booth, S. (1997). Learning and awareness. Mahwah, NJ: L. Erlbaum Associates.

Martorella, P. H. (1991). Knowledge and concept development in social Development. Handbook of research on Social Studies. In. R. S. James (Eds.), Studies teaching and learning (pp.370-384). New York: MacMillan.

McCulloch, W. S., \& Pitts, W. (1943). A logical calculus of the ideas immanent in nervous activity. The Bulletin of Mathematical Biophysics, 5(4), 115-133.

Milli Eğitim Bakanlığı (MEB) (2013). Ortaokul matematik dersi (5, 6, 7 ve 8. sinıflar) öğretim programı [Secondary mathematics book (5, 6, 7 and 8. class) programme of teaching]. Ankara: MEB.

Nabiyev, V. V. (2016). Yapay zekâ [Artificial intelligence]. Ankara: Seçkin Yayıncılık.

National Assessment of Educational Progress (NAEP) (2006). Civics 2006: The Nation's report card. Retrieved from http://nationsreportcare.gov/civics_2006/

National Council of Teachers of Mathematics (NCTM) (2006). Curriculum focal points. Reston, VA: Author.

National Council of Teachers of Mathematics (NCTM). (2000). Principles and standards for school mathematics. Reston, VA: National Council of Teachers of Mathematics.

Nordlander, M. C., \& Nordlander, E. (2012) On the concept image of complex numbers. International Journal of Mathematical Education in Science and Technology, 43(5), 627-641. 
Olkun, S., \& Toluk, Z. (2003). Illköğretimde etkinlik temelli matematik öğretimi [Activity based mathematics teaching in primary education]. Ankara: Anı Yayıncilık.

Olkun, S., Fidan, E., \& Özer, A. B. (2013). The development of number concept and the use of counting in problem solving of 5-7 year olds. Education and Science, 38(169), 236-248.

Organisation for Economic Co-operation and Development (OECD) (2004). Learning for tomorrow's world-first results from PISA 2003. Paris: OECD. Retrieved from http:// www.oecd.org/ dataoecd/1/60/-34002216.pdf

Organisation for Economic Co-operation and Development (OECD) (2016). PISA 2015 results in focus. OECD, Paris. Retrieved from http://www.oecd.org/pisa/

Rogers, J. P. (2008) Cardinal number and its representation: skills, concepts and contexts. Early Child Development and Care, 178(2), 211-225.

Sharma, S. S. (1996). Applied multivariate techiques. New York: John Wiley \& Sons.

Siegler, R. S. (1991). Children's thinking. Englewood Cliffs, NJ: Prentice Hall.

Tall, D., \& Vinner, S. (1981). Concept image and concept definition in mathematics with particular reference to limits and continuity. Educational Studies in Mathematics, 12(2), 151-169.

Tossavainen, T., Attorps, I., \& Väisänen, P. (2012). Some south african mathematics teachers' concept images of the equation concept. African Journal of Research in Mathematics, Science and Technology Education, 16(3), 376-389.

Trigwell, K. (2006). Phenomenography: An approach to researh into geography education. Journal of Geography in Higher Education, 30(2), 367-372.

Trovato, L. M. (2013). Developing number concepts. Childhood Education, 37(5), 226-229.

Van De Walle, J. A. (2004). Elementary and middle school mathematics. Teaching developmentally. Boston: Pearson Education/Allyn \& Bacon.

Vincent, B., LaRue, R., Sealey, V., \& Engelke, N. (2015). Calculus students' early concept images of tangent lines. International Journal of Mathematical Education in Science and Technology, 46(5), 641-657.

Vinner, S. (1983). Concept definition, concept image and the notion of function. International Journal of Education in Science and Technology, 14, 293-305.

Ward Jr, J. H. (1963). Hierarchical grouping to optimize an objective function. Journal of the American Statistical Association, 58(301), 236-244.

Wynn, K. (1992). Children's acquisition of the number words and the counting system. Cognitive Psychology, 24(2), 220-251.

Yesilbudak, M., Kahraman, H. T., \& Karacan, H. (2011). Object oriented agglomerative hierarchical clustering model in data mining. Journal of the Faculty of Engineering and Architecture of Gazi University, 26(1), 27-39. 


\section{APPENDIX 1}

\section{Inputs data for training the SOM-Ward Model}

\begin{tabular}{|c|c|c|c|c|c|c|c|c|c|c|c|}
\hline Students & $x_{1}$ & $x_{2}$ & $x_{3}$ & $\mathbf{x}_{4}$ & $x_{5}$ & Students & $x_{1}$ & $x_{2}$ & $x_{3}$ & $x_{4}$ & $x_{5}$ \\
\hline$S_{1}$ & 1 & 10 & 0 & 5.5 & 0 & $S_{107}$ & 7.5 & 4.2 & 0 & 4 & 0 \\
\hline $\mathrm{S}_{2}$ & 0 & 8.5 & 4.33 & 5 & 0 & $S_{108}$ & 4.5 & 8.5 & 1.5 & 0 & 0 \\
\hline$S_{3}$ & 0 & 0 & 5.5 & 0 & 0 & $S_{109}$ & 5.5 & 7.5 & 0 & 1.5 & 0 \\
\hline $\mathrm{S}_{4}$ & 9 & 0 & 5.33 & 4.4 & 8 & $S_{110}$ & 2 & 8.25 & 7 & 4.5 & 0 \\
\hline $\mathrm{S}_{5}$ & 10 & 3 & 0 & 5.25 & 0 & $S_{111}$ & 6.5 & 6.25 & 5.33 & 1 & 0 \\
\hline $\mathrm{S}_{6}$ & 6 & 5.5 & 0 & 4.66 & 0 & $S_{112}$ & 5 & 9 & 1.5 & 6.33 & 0 \\
\hline$S_{7}$ & 5.5 & 10 & 3 & 5.16 & 0 & $\mathrm{~S}_{113}$ & 5.2 & 5 & 0 & 9 & 0 \\
\hline $\mathrm{S}_{8}$ & 9 & 8.5 & 0 & 4.14 & 0 & $S_{114}$ & 5 & 0 & 7.5 & 0 & 0 \\
\hline $\mathrm{S}_{9}$ & 0 & 9.5 & 0 & 4.5 & 0 & $\mathrm{~S}_{115}$ & 2.5 & 8 & 7.4 & 0 & 0 \\
\hline$S_{10}$ & 0 & 0 & 0 & 5.5 & 0 & $S_{116}$ & 7 & 4.5 & 0 & 0 & 0 \\
\hline$S_{11}$ & 0 & 9 & 10 & 4.5 & 0 & $S_{117}$ & 8.5 & 5 & 0 & 2 & 0 \\
\hline$S_{12}$ & 0 & 7 & 9 & 3.83 & 0 & $\mathrm{~S}_{118}$ & 4 & 9 & 4.75 & 4.66 & 0 \\
\hline $\mathrm{S}_{13}$ & 6 & 8.5 & 8.5 & 3 & 0 & $\mathrm{~S}_{119}$ & 4 & 8 & 0 & 5.4 & 0 \\
\hline$S_{14}$ & 7 & 0 & 8.33 & 3.2 & 0 & $\mathrm{~S}_{120}$ & 0 & 0 & 0 & 5.5 & 0 \\
\hline $\mathrm{S}_{15}$ & 3.5 & 10 & 9 & 4.83 & 0 & $S_{121}$ & 6.5 & 4.83 & 0 & 0 & 0 \\
\hline$S_{16}$ & 0 & 10 & 8 & 4.625 & 0 & $S_{122}$ & 10 & 4.6 & 0 & 5.5 & 0 \\
\hline$S_{17}$ & 4.5 & 8 & 9 & 1.5 & 0 & $S_{123}$ & 7.5 & 5.33 & 0 & 3 & 0 \\
\hline $\mathrm{S}_{18}$ & 6.6 & 10 & 3 & 0 & 0 & $S_{124}$ & 3.66 & 8.33 & 8 & 0 & 0 \\
\hline$S_{19}$ & 3.5 & 7.66 & 0 & 6 & 0 & $\mathrm{~S}_{125}$ & 8.5 & 4 & 4 & 3.5 & 2 \\
\hline$S_{20}$ & 2.5 & 4.6 & 8 & 9.5 & 0 & $S_{126}$ & 5 & 5 & 0 & 10 & 0 \\
\hline$S_{21}$ & 7.5 & 6 & 6.5 & 3.75 & 0 & $\mathrm{~S}_{127}$ & 0 & 6 & 9.5 & 3.6 & 0 \\
\hline $\mathrm{S}_{22}$ & 3.5 & 9 & 8.33 & 0 & 0 & $S_{128}$ & 0 & 8 & 0 & 4.42 & 0 \\
\hline$S_{23}$ & 7 & 7 & 0 & 2 & 0 & $S_{129}$ & 0 & 10 & 5 & 5 & 0 \\
\hline $\mathrm{S}_{24}$ & 0 & 8.5 & 6 & 4.57 & 0 & $\mathrm{~S}_{130}$ & 0 & 0 & 5.5 & 0 & 0 \\
\hline$S_{25}$ & 6 & 0 & 0 & 5.28 & 0 & $S_{131}$ & 4.2 & 0 & 0 & 6.8 & 0 \\
\hline$S_{26}$ & 6.5 & 4 & 0 & 0 & 0 & $S_{132}$ & 7 & 4.75 & 0 & 1 & 0 \\
\hline $\mathrm{S}_{27}$ & 0 & 0 & 6.5 & 5.25 & 0 & $\mathrm{~S}_{133}$ & 0 & 5 & 4 & 8 & 0 \\
\hline$S_{28}$ & 0 & 0 & 10 & 5 & 0 & $S_{134}$ & 6.8 & 6 & 0 & 1.5 & 0 \\
\hline$S_{29}$ & 0 & 5 & 2 & 6.57 & 0 & $\mathrm{~S}_{135}$ & 9 & 7 & 5 & 4.85 & 0 \\
\hline $\mathrm{S}_{30}$ & 9 & 6 & 4.42 & 0 & 0 & $S_{136}$ & 7 & 5 & 7.66 & 2 & 0 \\
\hline$S_{31}$ & 7.33 & 8 & 0 & 3 & 5 & $S_{137}$ & 5.4 & 6 & 3 & 7 & 0 \\
\hline$S_{32}$ & 8 & 5.2 & 2.5 & 0 & 0 & $S_{138}$ & 8.5 & 5 & 5 & 2 & 0 \\
\hline$S_{33}$ & 3.5 & 9.5 & 8 & 7 & 0 & $S_{139}$ & 0 & 0 & 0 & 5.5 & 0 \\
\hline $\mathrm{S}_{34}$ & 4.5 & 9 & 5 & 0 & 0 & $\mathrm{~S}_{140}$ & 0 & 10 & 7 & 3.2 & 7.33 \\
\hline$S_{35}$ & 0 & 0 & 5.5 & 0 & 0 & $S_{141}$ & 4.5 & 7 & 8 & 4 & 0 \\
\hline$S_{36}$ & 4.5 & 4.5 & 7 & 0 & 0 & $S_{142}$ & 8 & 5 & 4 & 1.5 & 6 \\
\hline $\mathrm{S}_{37}$ & 0 & 10 & 5 & 5 & 0 & $S_{143}$ & 5.5 & 10 & 5 & 3 & 0 \\
\hline $\mathrm{S}_{38}$ & 0 & 0 & 7.5 & 5 & 0 & $S_{144}$ & 5.5 & 7 & 9 & 3.8 & 0 \\
\hline$S_{39}$ & 9 & 7.5 & 4.33 & 0 & 5 & $S_{145}$ & 5 & 9.5 & 0 & 4.2 & 0 \\
\hline $\mathrm{S}_{40}$ & 0 & 6.5 & 0 & 4.83 & 0 & $S_{146}$ & 6.5 & 7 & 3 & 2 & 0 \\
\hline $\mathrm{S}_{41}$ & 0 & 0 & 5.5 & 0 & 0 & $\mathrm{~S}_{147}$ & 0 & 0 & 5.5 & 0 & 0 \\
\hline$S_{42}$ & 4 & 8.25 & 3.66 & 3 & 0 & $S_{148}$ & 6.5 & 6.25 & 3 & 1 & 0 \\
\hline $\mathrm{S}_{43}$ & 8.5 & 4.66 & 0 & 1.5 & 4 & $\mathrm{~S}_{149}$ & 7 & 10 & 0 & 4.42 & 0 \\
\hline $\mathrm{S}_{44}$ & 8 & 9.5 & 3.5 & 4.2 & 0 & $S_{150}$ & 8.5 & 3 & 5.5 & 2.33 & 0 \\
\hline $\mathrm{S}_{45}$ & 0 & 2 & 0 & 5.87 & 6 & $S_{151}$ & 7.5 & 5 & 10 & 2.5 & 0 \\
\hline$S_{46}$ & 6.4 & 10 & 2 & 4.5 & 0 & $S_{152}$ & 7.5 & 4.2 & 4 & 0 & 0 \\
\hline$S_{47}$ & 8 & 9 & 4.25 & 5.25 & 0 & $S_{153}$ & 6.5 & 9 & 0 & 4.25 & 3 \\
\hline $\mathrm{S}_{48}$ & 7.5 & 0 & 6.66 & 4 & 0 & $S_{154}$ & 6 & 2 & 4.5 & 6.5 & 0 \\
\hline $\mathrm{S}_{49}$ & 0 & 10 & 5.83 & 3.33 & 0 & $\mathrm{~S}_{155}$ & 5.75 & 3.33 & 7.33 & 0 & 0 \\
\hline$S_{50}$ & 5 & 8 & 3 & 5.75 & 0 & $S_{156}$ & 7.5 & 6 & 4 & 2.5 & 0 \\
\hline$S_{51}$ & 5 & 9.5 & 8 & 1.5 & 0 & $\mathrm{~S}_{157}$ & 5 & 5 & 3 & 6.75 & 0 \\
\hline$S_{52}$ & 6.6 & 3.5 & 7 & 4 & 0 & $S_{158}$ & 0 & 0 & 5.5 & 0 & 0 \\
\hline$S_{53}$ & 0 & 4.8 & 7.33 & 4.5 & 0 & $S_{159}$ & 0 & 0 & 5.5 & 0 & 0 \\
\hline$S_{54}$ & 6.5 & 10 & 3.8 & 0 & 0 & $S_{160}$ & 4.5 & 10 & 0 & 5.4 & 0 \\
\hline
\end{tabular}




\begin{tabular}{|c|c|c|c|c|c|c|c|c|c|c|c|}
\hline Students & $\mathbf{x}_{1}$ & $x_{2}$ & $x_{3}$ & $\mathbf{x}_{4}$ & $\mathbf{x}_{5}$ & Students & $\mathbf{x}_{1}$ & $\mathbf{x}_{2}$ & $x_{3}$ & $x_{4}$ & $x_{5}$ \\
\hline $\mathrm{S}_{55}$ & 7.5 & 10 & 0 & 3 & 0 & $S_{161}$ & 5.6 & 9 & 0 & 4.5 & 0 \\
\hline $\mathrm{S}_{56}$ & 5.6 & 7 & 0 & 4.33 & 0 & $\mathrm{~S}_{162}$ & 0 & 8 & 2 & 6.25 & 0 \\
\hline $\mathrm{S}_{57}$ & 6.8 & 9 & 6 & 2 & 0 & $\mathrm{~S}_{163}$ & 0 & 9 & 7 & 3.5 & 0 \\
\hline $\mathrm{S}_{58}$ & 4.66 & 7 & 8 & 4.75 & 0 & $S_{164}$ & 6.5 & 10 & 0 & 3.8 & 0 \\
\hline$S_{59}$ & 2 & 7 & 0 & 0 & 0 & $\mathrm{~S}_{165}$ & 8 & 9.5 & 0 & 3.83 & 5 \\
\hline$S_{60}$ & 6.66 & 7.5 & 4 & 0 & 0 & $S_{166}$ & 4.83 & 9.5 & 0 & 3.5 & 0 \\
\hline$S_{61}$ & 8.25 & 4.25 & 2.5 & 0 & 0 & $\mathrm{~S}_{167}$ & 8.5 & 6.5 & 10 & 3 & 0 \\
\hline$S_{62}$ & 6.5 & 4.75 & 0 & 5 & 0 & $\mathrm{~S}_{168}$ & 7.5 & 10 & 0 & 3 & 0 \\
\hline$S_{63}$ & 8 & 4.4 & 1 & 0 & 0 & $\mathrm{~S}_{169}$ & 7 & 5 & 0 & 3.5 & 0 \\
\hline $\mathrm{S}_{64}$ & 9 & 10 & 0 & 4.5 & 0 & $\mathrm{~S}_{170}$ & 7.5 & 5.66 & 0 & 2.66 & 0 \\
\hline $\mathrm{S}_{65}$ & 2.5 & 0 & 7.5 & 0 & 0 & $S_{171}$ & 7.8 & 3 & 0 & 3.5 & 0 \\
\hline$S_{66}$ & 0 & 10 & 0 & 5.37 & 2 & $S_{172}$ & 6.5 & 9.5 & 0 & 2.5 & 0 \\
\hline$S_{67}$ & 0 & 7.66 & 4.6 & 4.5 & 0 & $\mathrm{~S}_{173}$ & 0 & 0 & 5.5 & 0 & 0 \\
\hline$S_{68}$ & 2.5 & 7 & 7 & 0 & 10 & $S_{174}$ & 5 & 5.5 & 8 & 4 & 0 \\
\hline$S_{69}$ & 7 & 9 & 3.5 & 0 & 0 & $\mathrm{~S}_{175}$ & 7.5 & 4.16 & 0 & 0 & 0 \\
\hline$S_{70}$ & 3.5 & 7.2 & 5 & 0 & 0 & $\mathrm{~S}_{176}$ & 7.5 & 6.8 & 2.5 & 1 & 0 \\
\hline$S_{71}$ & 7.5 & 3.5 & 0 & 4.5 & 0 & $S_{177}$ & 7 & 6 & 3.66 & 6.5 & 4 \\
\hline $\mathrm{S}_{72}$ & 4 & 5 & 8 & 0 & 0 & $\mathrm{~S}_{178}$ & 7.66 & 7 & 4 & 3.5 & 3 \\
\hline$S_{73}$ & 4.5 & 8.5 & 5 & 0 & 0 & $S_{179}$ & 5.5 & 8.5 & 10 & 2.5 & 1 \\
\hline $\mathrm{S}_{74}$ & 4.57 & 7 & 9 & 0 & 0 & $S_{180}$ & 6 & 7.33 & 0 & 1.5 & 0 \\
\hline $\mathrm{S}_{75}$ & 4.5 & 6 & 5 & 9 & 0 & $S_{181}$ & 3 & 9 & 0 & 7.75 & 0 \\
\hline$S_{76}$ & 5.5 & 4 & 10 & 0 & 0 & $\mathrm{~S}_{182}$ & 2.5 & 9 & 0 & 6 & 6 \\
\hline $\mathrm{S}_{77}$ & 5.66 & 7.66 & 3.75 & 0 & 0 & $S_{183}$ & 8 & 10 & 2.5 & 6 & 9 \\
\hline $\mathrm{S}_{78}$ & 0 & 4.75 & 4.75 & 8.5 & 0 & $\mathrm{~S}_{184}$ & 5.5 & 6 & 5 & 0 & 0 \\
\hline$S_{79}$ & 6.5 & 5 & 0 & 5.4 & 0 & $\mathrm{~S}_{185}$ & 6 & 10 & 4 & 5 & 0 \\
\hline $\mathrm{S}_{80}$ & 1 & 5.875 & 7 & 0 & 0 & $S_{186}$ & 6 & 6.5 & 0 & 4.6 & 0 \\
\hline $\mathrm{S}_{81}$ & 7.5 & 5 & 0 & 4 & 0 & $\mathrm{~S}_{187}$ & 0 & 8.25 & 3.66 & 0 & 0 \\
\hline $\mathrm{S}_{82}$ & 6.4 & 10 & 0 & 3.25 & 0 & $\mathrm{~S}_{188}$ & 6 & 6.66 & 2.5 & 0 & 0 \\
\hline $\mathrm{S}_{83}$ & 7 & 4.33 & 6 & 4 & 0 & $S_{189}$ & 7 & 5 & 9.5 & 4 & 0 \\
\hline $\mathrm{S}_{84}$ & 7 & 3 & 4.25 & 0 & 0 & $S_{190}$ & 6 & 7 & 0 & 3.75 & 0 \\
\hline $\mathrm{S}_{85}$ & 5.14 & 6.33 & 0 & 0 & 0 & $\mathrm{~S}_{191}$ & 7 & 10 & 8 & 3.2 & 0 \\
\hline $\mathrm{S}_{86}$ & 7.5 & 6.33 & 2 & 3 & 1 & $S_{192}$ & 8.5 & 10 & 0 & 3.66 & 6 \\
\hline $\mathrm{S}_{87}$ & 3.5 & 8.5 & 6.5 & 4.5 & 0 & $\mathrm{~S}_{193}$ & 0 & 6.6 & 0 & 4.4 & 0 \\
\hline $\mathrm{S}_{88}$ & 8 & 4.33 & 6 & 4 & 0 & $\mathrm{~S}_{194}$ & 0 & 9 & 5 & 3.25 & 0 \\
\hline $\mathrm{S}_{89}$ & 7.2 & 9 & 3.5 & 1.5 & 0 & $S_{195}$ & 7.5 & 4 & 0 & 4.5 & 0 \\
\hline $\mathrm{S}_{90}$ & 5.8 & 7.66 & 2 & 0 & 1 & $\mathrm{~S}_{196}$ & 10 & $\begin{array}{l}6.5 \\
\end{array}$ & 0 & 4.57 & 0 \\
\hline $\mathrm{S}_{91}$ & 7.5 & 9 & 4.8 & 0 & 3.5 & $\mathrm{~S}_{197}$ & 7 & 4.5 & 0 & 0 & 0 \\
\hline $\mathrm{S}_{92}$ & 7.5 & 10 & 3 & 0 & 0 & $S_{198}$ & 6.5 & 4.83 & 0 & 0 & 0 \\
\hline $\mathrm{S}_{93}$ & 8 & 6 & 0 & 3.66 & 0 & $\mathrm{~S}_{199}$ & 5.25 & 7.5 & 0 & 4.75 & 0 \\
\hline $\mathrm{S}_{94}$ & 0 & 7 & 0 & 4.85 & 0 & $S_{200}$ & 5.4 & 7 & 6 & 2 & 0 \\
\hline $\mathrm{S}_{95}$ & 5 & 9 & 0 & 3.25 & 0 & $S_{201}$ & 0 & 9 & 0 & 5.11 & 0 \\
\hline $\mathrm{S}_{96}$ & 8 & 5.5 & 7 & 3.5 & 0 & $\mathrm{~S}_{202}$ & 0 & 9.5 & 6 & 2 & 0 \\
\hline $\mathrm{S}_{97}$ & 1 & 5.5 & 0 & 6.14 & 0 & $\mathrm{~S}_{203}$ & 7.5 & 4.16 & 0 & 0 & 0 \\
\hline $\mathrm{S}_{98}$ & 10 & 7.5 & 0 & 3 & 0 & $\mathrm{~S}_{204}$ & 4.16 & 6.5 & 8.5 & 0 & 0 \\
\hline $\mathrm{S}_{99}$ & 0 & 6.5 & 4 & 5.42 & 0 & $\mathrm{~S}_{205}$ & 0 & 9 & 1 & 5.14 & 0 \\
\hline$S_{100}$ & 1 & 5.5 & 10 & 0 & 0 & $\mathrm{~S}_{206}$ & 4.8 & 4.66 & 0 & 8.5 & 0 \\
\hline$S_{101}$ & 4.5 & 8 & 0 & 4.33 & 0 & $\mathrm{~S}_{207}$ & 0 & 10 & 4.5 & 0 & 9 \\
\hline $\mathrm{S}_{102}$ & 2.5 & 8.33 & 5 & 7.5 & 0 & $\mathrm{~S}_{208}$ & 0 & 7.2 & 0 & 3.8 & 0 \\
\hline $\mathrm{S}_{103}$ & 2.5 & 6.66 & 0 & 6 & 0 & $S_{209}$ & 6.5 & 4.5 & 9 & 2 & 0 \\
\hline $\mathrm{S}_{104}$ & 4 & 5.5 & 0 & 8.5 & 0 & $S_{210}$ & 0 & 0 & 5.5 & 0 & 0 \\
\hline $\mathrm{S}_{105}$ & 6.2 & 5.75 & 0 & 1 & 0 & $\mathrm{~S}_{211}$ & 7 & 4 & 0 & 5 & 4 \\
\hline $\mathrm{S}_{106}$ & 6.25 & 4.75 & 0 & 5.5 & 0 & $\mathrm{~S}_{212}$ & 6.5 & 4.83 & 0 & 0 & 0 \\
\hline
\end{tabular}

\section{http://www.ejmste.com}

